Mathematics for Chemists 


\title{
MATHEMATICS FOR CHEMISTS
}

\author{
D. M. Hirst
}

Department of Molecular Sciences,

University of Warwick, Coventry

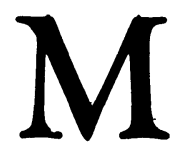


(c) D. M. Hirst 1976

A11 rights reserved. No part of this publication may be reproduced or transmitted, in any form or by any means, without permission.

First published 1976 by

THE MACMILLAN PRESS LTD

London and Basingstoke

Associated companies in New York Dublin

Melbourne Johannesburg and Madras

SBN 333181727

ISBN 978-1-349-02587-9 ISBN 978-1-349-02585-5 (eBook)

DOI 10.1007/978-1-349-02585-5

Typeset by

PREFACE LTD

Salisbury, wilts

This book is sold subject to the standard conditions of the Net Book Agreement.

The paperback edition of this book is sold subject to the condition that it shall not, by way of trade or otherwise, be lent, re-sold, hired out, or otherwise circulated without the publisher's prior consent in any form of binding or cover other than that in which it is published and without a similar condition including this condition being imposed on the subsequent purchaser. 


\section{Contents}

Preface

$\mathrm{xi}$

1 REVIEW OF BASIC MATERIAL - FUNCTIONS, INEQUALITIES 1

1.1 Functions

1.1.1 Graphical representation of functions 1

1.1.2 Types of function 2

1.1.3 Trigonometric functions $\quad 6$

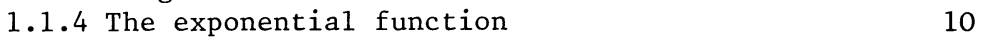

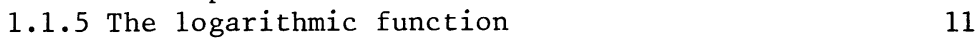

$\begin{array}{ll}1.1 .6 \text { Hyperbolic functions } & 12\end{array}$

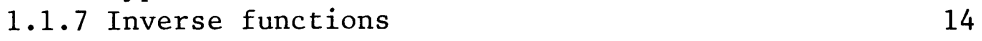

$\begin{array}{ll}1.2 \text { Inequalities } & 16\end{array}$

$\begin{array}{ll}1.3 \text { Problems for Solution } & 16\end{array}$

2 DIFFERENTIAL CALCULUS 19

2.1 Limits 19

2.2 Continuity 21

2.3 The Derivative $\quad 22$

2.4 Rules for Differentiation $\quad 24$

2.4.1 Derivatives of powers of $\mathrm{x} \quad 24$

2.4.2 The derivative of a sum 25

2.4.3 The derivative of a product 26

2.4.4 The derivative of a quotient 26

2.4.5 The chain rule 27

2.4.6 Derivatives of the trigonometric functions 28

2.4.7 The exponential function 29

2.4.8 The logarithmic function $x \quad 30$

2.4.9 The generalised exponential $\mathrm{a}^{\mathrm{x}} 30$

2.4.10 Hyperbolic functions 31

2.4.11 Inverse trigonometric functions 31

2.5 Higher Derivatives 32

2.6 Applications of Differentiation 33

2.6.1 Rate of change 33

2.6.2 Slope of a curve, maxima and minima 34

$\begin{array}{ll}2.6 .3 \text { Curve tracing } & 37\end{array}$

2.7 Increments and Differentials 38

2.8 Differentiation of Implicit Functions $\quad 41$

2.9 Logarithmic Differentiation $\quad 41$

2.10 Problems for Solution $\quad 42$

3 INTEGRATION $\quad 45$

3.1 The Indefinite Integral 45 
3.2 Methods of Integration $\quad 46$

3.2.1 Standard integrals $\quad 46$

$\begin{array}{ll}3.2 .2 \text { Method of substitution } & 47\end{array}$

3.2.3 Transformation of trigonometric integrands 51

3.2.4 Integration by parts 52

3.2.5 Integration of algebraic fractions 55

3.3 The Particular Integral 60

3.4 The Definite Integral 61

3.4.1 Properties of definite integrals 61

3.4.2 Improper integrals 63

3.5 The Definite Integral as a Summation 64

3.6 Applications of the Definite Integral 65

3.6.1 Area under a curve 65

$\begin{array}{ll}3.6 .2 \text { Work done by a force } & 68\end{array}$

3.6.3 Volumes of solids of revolution $\quad 69$

$\begin{array}{ll}3.6 .4 \text { Length of arc } & 70\end{array}$

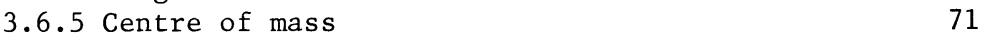

$\begin{array}{ll}3.6 .6 \text { Moment of inertia } & 75\end{array}$

$\begin{array}{ll}3.6 .7 \text { Mean values } & 78\end{array}$

3.6.8 Probability and weighted means 80

3.7 Multiple Integrals $\quad 82$

$\begin{array}{ll}3.8 \text { Problems for Solution } & 87\end{array}$

4 FUNCTIONS OF MANY VARIABLES - PARTIAL DIFFERENTIATION 90

4.1 Definition of Partial Derivatives 90

4.2 Geometrical Interpretation of the Partial Derivative 92

4.3 Higher Derivatives 93

4.4 Change of Variable 94

4.4.1 First derivative 94

$\begin{array}{lr}4.4 .2 \text { Second derivative } & 97\end{array}$

4.4.3 Spherical polar co-ordinates 101

4.5 The Total Differential 103

$\begin{array}{ll}4.6 \text { Implicit Functions } & 106\end{array}$

4.6.1 Functions of a single variable 106

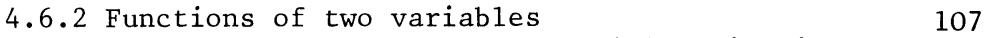

4.6.3 A useful relation between partial derivatives 108

4.7 The Legendre Transformation and Maxwe11's Relations 108

4.8 Line Integrals 110

$\begin{array}{ll}4.9 \text { Problems for Solution } & 113\end{array}$

5 VECTORS 116

5.1 Vector Algebra 116

5.2 Resolution of a Vector 118

5.3 Products of Vectors 120

5.3 .1 Scalar product 120

5.3.2 Vector product 123

5.3.3 Triple products 126

5.4 Derivatives of Vectors $\quad 129$

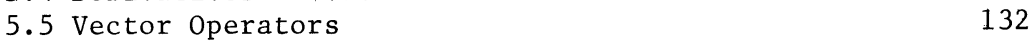

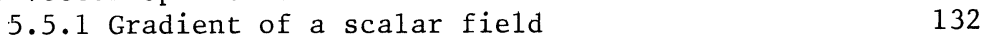

$\begin{array}{ll}5.5 .2 \text { Divergence of a vector field } & 134\end{array}$

5.5.3 Cur1 of a vector field 135

5.6 Problems for Solution 136 
6.1 Simple Series $\quad 139$

$\begin{array}{ll}6.1 .1 \text { Arithmetic progression } & 139\end{array}$

6.1.2 Geometric progression 140

$\begin{array}{ll}6.2 \text { Convergence of Infinite Series } & 140\end{array}$

$\begin{array}{ll}6.3 \text { Tests for Convergence } & 141\end{array}$

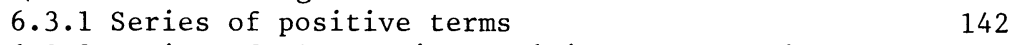

6.3.2 Series of alternating positive and negative terms 143

6.4 Power Series 145

6.5 Taylor and Maclaurin Series $\quad 146$

6.5.1 Binomial expansion 148

$\begin{array}{ll}6.5 .2 \text { Sine and cosine series } & 149\end{array}$

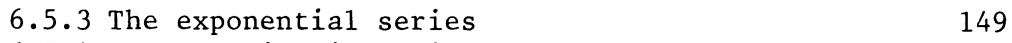

6.5.4 The logarithmic series $\quad 150$

$\begin{array}{ll}6.5 .5 \text { Legendre polynomials } & 150\end{array}$

6.6 Differentiation or Integration of Series 151

6.7 Problems for Solution 151

7 COMPLEX NUMBERS

7.1 Definition 153

$\begin{array}{ll}7.2 \text { Algebra of Complex Numbers } & 154\end{array}$

$\begin{array}{ll}7.2 .1 \text { Addition and subtraction } & 154\end{array}$

$\begin{array}{ll}7.2 .2 \text { Multiplication } & 154\end{array}$

7.2.3 Division 155

$\begin{array}{ll}7.2 .4 \text { Complex conjugate } & 155\end{array}$

7.2.5 Modulus of a complex number 155

7.3 The Argand Diagram 156

7.3.1 Cartesian co-ordinates $\quad 156$

$\begin{array}{ll}\text { 7.3.2 The Argand diagram in polar co-ordinates } & 157\end{array}$

7.3.3 Multiplication in the Argand diagram 158

7.3.4 Division 158

7.4 De Moivre's Theorem 159

7.4.1 Application to trigonometric formulae 160

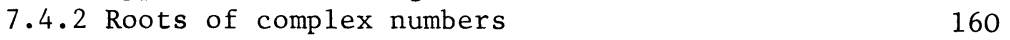

$\begin{array}{ll}7.5 \text { The Exponential Function } & 161\end{array}$

$\begin{array}{ll}7.6 \text { Problems for Solution } & 163\end{array}$

8 ORTHOGONAL FUNCTIONS AND FOURIER SERIES 166

8.1 The Relation between Vectors and Functions 166

8.2 Expansion in Terms of Orthogonal Functions 168

$\begin{array}{ll}8.3 \text { Fourier Series } & 169\end{array}$

8.4 The Fourier Transform 174

8.5 Problems for Solution $\quad 175$

9 DETERMINANTS 177

9.1 Simultaneous Equations and Determinants 177

$\begin{array}{ll}9.1 .1 \text { Second-order determinants } & 177\end{array}$

9.1.2 Third-order determinants 178

9.1.3 Determinants of general order 180

$\begin{array}{ll}9.2 \text { Properties of Determinants } & 181\end{array}$

9.3 Minors and Cofactors 186

$\begin{array}{ll}9.4 \text { Solution of Linear Equations } & 187\end{array}$ 


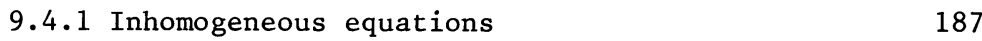

$\begin{array}{ll}9.4 .2 \text { Homogeneous equations } & 188\end{array}$

$\begin{array}{ll}\text { 9.5 Problems for Solution } & 191\end{array}$

10 MATRICES 194

10.1 Matrix Algebra 194

$\begin{array}{ll}10.1 .1 \text { Matrix addition } & 194\end{array}$

$\begin{array}{ll}10.1 .2 \text { Equality of matrices } & 195\end{array}$

$\begin{array}{ll}10.1 .3 \text { Multiplication by a constant } & 195\end{array}$

10.1.4 Matrix multiplication $\quad 195$

10.2 Some Important Special Matrices 197

10.2.1 Row and column vectors 197

10.2.2 Nul1 matrix 199

10.2.3 Square matrix 199

10.2.4 Diagonal matrix 199

10.2.5 The unit matrix 200

10.2.6 Determinant of a matrix 200

10.2.7 Transpose of a matrix 200

10.2.8 Symmetric matrix 202

10.2.9 Complex matrices $\quad 202$

10.2.10 The inverse matrix 203

10.2.11 Orthogonal and unitary matrices 205

10.3 Solution of Simultaneous Equations 205

10.4 Eigenvalues and Eigenvectors 206

10.5 Linear Transformations 208

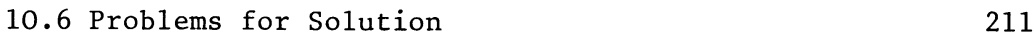

11 DIFFERENTIAL EQUATIONS 213

11.1 Classification of Ordinary Differential Equations and their Solutions 214

11.2 Equations of First Order and First Degree $\quad 214$

$\begin{array}{ll}11.2 .1 \text { Simple equations } & 214\end{array}$

$\begin{array}{ll}11.2 .2 \text { Variables separable } & 214\end{array}$

$\begin{array}{ll}11.2 .3 \text { Homogeneous equations } & 215\end{array}$

$\begin{array}{ll}11.2 .4 \text { Exact differential equations } & 216\end{array}$

11.2 .5 Linear equations 218

11.3 First-order Equations of Higher Degree 220

11.4 Linear Second-order Differential Equations 220

11.4.1 Solution of the homogeneous equation 221

11.4.2 Solution of the inhomogeneous equation 226

11.5 Problems for Solution $\quad 230$

12 PARTIAL DIFFERENTIAL EQUATIONS 234

12.1 The Wave Equation $\quad 234$

12.2 The Schrödinger Equation $\quad 237$

$\begin{array}{ll}12.3 \text { Problems for Solution } & 240\end{array}$

13 NUMERICAL METHODS 242

13.1 Newton's Method for the Solution of Nonlinear
Equations

13.2 Numerical Integration or Quadrature $\quad 244$ 13.2.1 Trapezoidal rule 245 
13.2.2 Simpson's rule

13.2.3 Newton-Cotes formulae 248

$\begin{array}{ll}13.2 .4 \text { Gaussian quadrature } & 248\end{array}$

13.3 Numerical Solution of Ordinary Differential Equations 249

13.3.1 Taylor-series solution $\quad 250$

13.3.2 The Runge-Kutta method 250

13.3.3 Predictor-corrector methods 253

13.4 Solution of Simultaneous Linear Equations, Evaluation of a Determinant and the Inverse Matrix 254

$\begin{array}{ll}13.5 \text { Problems for Solution } & 257\end{array}$

14 ELEMENTARY STATISTICS AND ERROR ANALYSIS 259

$\begin{array}{ll}14.1 \text { Errors } & 259\end{array}$

14.2 Frequency Distributions $\quad 259$

14.3 The Normal Distribution 265

$\begin{array}{ll}14.4 \text { Sampling } & 266\end{array}$

14.5 The Method of Least Squares and Curve Fitting 267

$\begin{array}{ll}\text { 14.5.1 Principle of least squares } & 267\end{array}$

14.5.2 Fitting of data to a linear function 268

14.5.3 Fitting of data to other functions 272

14.6 Significance Tests 273

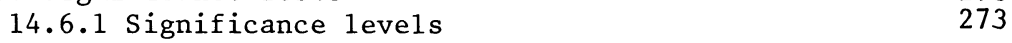

$\begin{array}{ll}14.6 .2 \text { The u-test } & 274\end{array}$

$\begin{array}{ll}14.6 .3 \text { Student's t-test } & 276\end{array}$

$\begin{array}{ll}14.6 .4 \text { The } x^{2} \text {-test } & 277\end{array}$

$\begin{array}{ll}14.7 \text { Problems for Solution } & 279\end{array}$

$\begin{array}{ll}\text { Bibliography } & 281\end{array}$

$\begin{array}{ll}\text { Answers to Problems } & 283\end{array}$

$\begin{array}{lr}\text { Index } & 294\end{array}$ 


\section{Preface}

A sound knowledge of the elementary aspects of many areas of mathematics is indispensible to the study of the quantitative aspects of chemistry. This book presents the mathematics required for the study of chemistry to honours degree level in British universities and polytechnics. The material presented should also be suitable for chemistry majors and first-year graduate students in North American universities. It has evolved from a course of lectures given over the past ten years to first-year students in Molecular and Biological Sciences at the University of Warwick.

Students of chemistry have, in general, a more limited mathematical background than physics or engineering students. This book does not assume that the student has followed an $\mathrm{A}-1$ evel or other post-0-1evel course in mathematics. Therefore the calculus is developed from first principles. The approach is descriptive rather than formal in that the emphasis is on the application of mathematical techniques rather than on the proving of theorems. Some results are quoted without proof where the derivation is more confusing than illuminating.

Wherever possible, mathematical techniques and ideas have been illustrated with chemical examples. It has often been necessary to present applications without explaining the underlying theory; for a full explanation the reader should consult texts on physical or quantum chemistry such as those included in the bibliography.

The material presented here should prepare the student for the study of quantum mechanics and group theory. A chapter on group theory has not been included because it was felt that the topic could not be adequately covered in one chapter and because many excellent texts on group theory in chemistry are available.

Numerical and statistical methods are becoming increasingly important in the analysis of experimental data. Introductory chapters on these topics have been included to give the student some background before he consults more complete treatments of these subjects.

Several problems, indicated by '(U.W.)', have appeared in University of Warwick examinations. The copyright for these problems is vested in the University of Warwick and the author is grateful for permission to reproduce them here.

The author is grateful to Dr S. P. Liebmann who read much of the manuscript and to Mr M. S. Hunt and Professor P. J. Harrison for reading chapters 13 and 14 , respectively. 